\title{
Oral dosing of dexamethasone was as effective as intramuscular dosing for outpatient treatment of children with moderate croup
}

\author{
Rittichier KK, Ledwith CA. Outpatient treatment of moderate croup with dexamethasone: intramuscular versus oral \\ dosing. Pediatrics 2000 Dec;106:1344-8.

\section{QUESTION: Is oral administration of dexamethasone as effective as intramuscular administration for outpatient treatment of children with moderate croup?}

\section{Design}

Randomised (allocation not concealed), blinded (outcome assessors), controlled trial with follow up at 48-72 hours after the acute care visit.

\section{Setting}

The emergency department of a children's hospital in Denver, Colorado, USA.

\section{Patients}

317 children who were 3 months to 12 years of age, had moderate croup (defined as a clinical syndrome of hoarseness and barky cough associated with a presence or history of stridor at rest and/or retractions), and onset of illness for $<48$ hours. Exclusion criteria were epiglottitis, foreign body aspiration, reactive airway exacerbation, acute bacterial pneumonia, acquired or congenital upper airway anomaly, immunocompromised status, or steroid exposure during the previous 2 weeks. 277 children (87\%) were included in the analysis (median age 2 y, $69 \%$ boys).

\section{Intervention}

138 children received oral dexamethasone, given as a crushed tablet mixed with flavoured syrup or jelly, and 139 received intramuscular dexamathasone. Both oral and intramuscular dexamethasone were given as a single dose of $0.6 \mathrm{mg} / \mathrm{kg}$ (maximum $8 \mathrm{mg}$ ).

\section{Main outcome measures}

Main outcome was parent reported need for further treatment after the initial emergency department visit, which could include re-evaluation at a primary care provider's office, additional steroids or racemic epinephrine, or admission to hospital. A secondary outcome was parent reported improvement of symptoms.

\section{Main results}

At 48-72 hours, children who received oral dosing did not differ from those who received intramuscular dosing for unscheduled return visits to a healthcare facility or a primary care provider's office $(25 \% v 32 \%, \mathrm{p}=0.2)$, need for additional steroids $(9 \% v 8 \%, \mathrm{p}=0.81)$ or subsequent racemic epinephrine $(2 \% v 1 \%, \mathrm{p}=0.68)$, or hospital admissions ( $1 \% v 1 \%, \mathrm{p}=1.0)$. Overall, children who received oral dosing did not differ from those who received intramuscular dosing for parent reported need for further treatment after the initial emergency department visit $(9 \% v 8 \%, \mathrm{p}=0.81)$. They also did not differ for parent reported resolution of all symptoms $(48 \%$ ข $54 \%, \mathrm{p}=0.31)$.

\section{Conclusion}

Children with moderate croup who received oral dosing of dexamethasone did not differ from those who received intramuscular dosing for parent reported need for further treatment after an initial emergency department visit and for parent reported symptom resolution.

\section{COMMENTARY}

Glucocorticoids such as dexamethasone and budesonide have been shown to be effective in the treatment of children with croup. ${ }^{1}$ This study by Rittichier and Ledwith is the first study to directly compare oral and intramuscular routes of administration of dexamethasone. The similar number of children in each group needing further treatment after an initial visit to the emergency department supports the idea that oral dexamethasone is as clinically effective as intramuscular dexamethasone for treatment of outpatient croup.

Study strengths include the use of a randomised, controlled design, blinding of outcome assessors, and sufficient power to detect a difference in effect between groups. The main outcome measure was parent report of subsequent visits for additional croup treatment.

The results are relevant to paediatric and child health nurses and will be of particular interest to those working in the community, emergency departments, and on general paediatric/medical wards. Children fear injections, ${ }^{2}$ and even very young children retain memories of painful procedures, which affect their subsequent reactions to painful procedures. ${ }^{3}$ The pain and risks associated with injections can be avoided by giving dexamethasone orally rather than by intramuscular injection. The authors explain that both oral and intramuscular dexamethasone are fairly inexpensive, and no additional financial benefit would be gained from using one or the other. There is some evidence of an increased incidence of vomiting with the oral preparation ${ }^{4}$; however, in this study only 1 patient vomited the initial dose of oral dexamethasone and later tolerated a repeat oral dose. Crushing the tablets and mixing the pill fragments with flavoured syrup or jelly may have made the oral dose easier to tolerate. The findings suggest that oral dexamethasone should be considered the treatment of choice for children presenting to the emergency department with moderate croup.

Alison Twycross, RGN, RMN, RSCN, MSc Lecturer in Health Sciences University of Nottingham Nottingham, UK

1 Ausejo M, Saenz A, Pham B, et al. Glucocorticoids for croup. Cochrane Database Syst Rev 2001;(1): latest version 11 Jun 1999

2 Mather L, Mackie J. The incidence of postoperative pain in children. Pain 1983;15:271-82.

3 Grunau RE, Whitfield MF, Petrie J, et al. Children's judgements about pain at age 8-10 years: do extremely low birthweight $(<$ or $=1000 \mathrm{~g}$ ) children differ from full birthweight peers? J Child Psychol Psychiatry 1998:39:587-94.

4 Madhok M, Kost SI, Laffey SP, et al. Nebulized versus oral dexamethasone for the treatment of mild to moderate croup. Abstract and poster presentation at pediatric academic societies' annual meeting; May 1-4, 1999: San Francisco, California. 